\title{
Analysis of Concrete-encased CFST Stub Columns under Axial Compression after Exposure to Fire
}

\author{
Minghao YU \\ School of Civil Engineering \\ Shenyang Jianzhu University \\ Shenyang, China \\ Wendong DUN \\ School of Civil Engineering \\ Shenyang Jianzhu University \\ Shenyang, China
}

\author{
Debin REN \\ School of Civil Engineering \\ Shenyang Jianzhu University \\ Shenyang, China \\ Qingxin REN \\ School of Civil Engineering \\ Shenyang Jianzhu University \\ Shenyang, China \\ E-mail: renqingxin@sjzu.edu.cn
}

\begin{abstract}
This paper presents the behavior of concrete-encased CFST stub columns under axial compression after exposure to fire from both experiment and numerical analysis. ABAQUS is used to develop a finite element analysis (FEA) model to investigate the performance of the composite columns after exposure to fire. Two groups (10 specimens) of concreteencased CFST stub columns with different CFST ratio and fire duration time were tested. The FEA model was verified by comparison with test results. The work of this paper provides a reference for further theoretical study on concrete-encased CFST stub columns after exposure to fire.
\end{abstract}

Keywords-component; concrete-encased CFST stub columns; axial compression; post fire; load-bearing capacity; finite element analysis

\section{INTRODUCTION}

In China, concrete-encased CFST columns have been gradually used in high-rise buildings in recent years [1].

The concrete-encased CFST column is a type of composite member which consists of inner concrete filled steel tube (CFST) and outer reinforced concrete (RC). The tube inside is full of concrete and its outside is encased by the concrete too. Fig. 1 shows the cross-section of the concrete-encased CFST column.

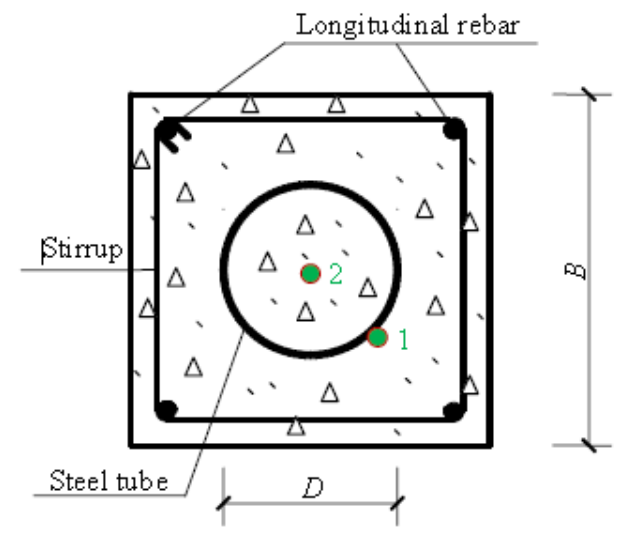

Figure 1. Cross-section of concrete-encased CFST stub columns
In the past, a series of studies on the concrete-encased CFST column were carried out. However, there is still a lack of information on the composite member under axial compression after exposed to fire. It indicates a need for further study in this area. A theoretical model that calculates the ultimate axial compressive strength of the composite stub column after exposed to fire was described in this paper and was verified by comparison with test results.

\section{FinITE ELEMENT MODEL}

\section{A. Temperature Field}

The temperature of the column was calculated by the software ABAQUS. The columns were heated 30min or 60min following ISO-834 standard fire curve. The thermal conductivity, specific heat, thermal expansion and other thermal properties of steel and concrete presented by Han et al. (2015) [2] were adopted in this paper. The temperature of an element in cross-section was assumed to be equal to the temperature at its center. The 4-node heat transfer quadrilateral shell elements were used for steel tube; the 8node linear heat transfer brick elements were used for shaped concrete; the 2-node heat transfer link elements were used for longitudinal bar and stirrup. The thermal boundary conditions are shown in Fig. 2.

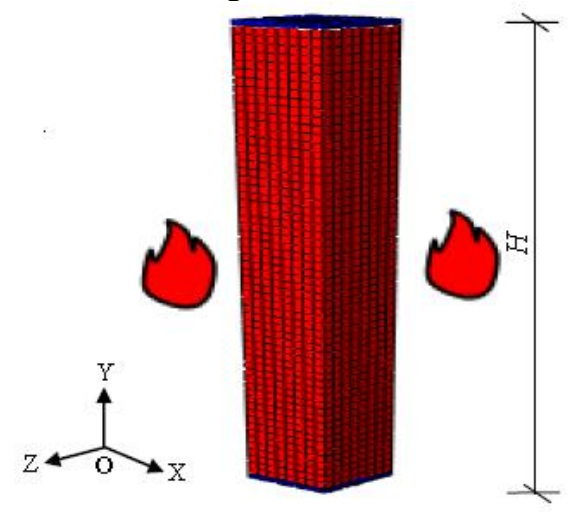

Figure 2. FEA model in fire 


\section{B. Material Properties}

The basic parameters of columns: $H=600 \mathrm{~mm} B=200 \mathrm{~mm}$ (the width of cross-section) $f_{\text {cu, in }}=60 \mathrm{MPa}, f_{\text {cu, out }}=40 \mathrm{MPa}$, $f_{\mathrm{sy}}=345 \mathrm{MPa}, f_{\mathrm{sy}, \mathrm{sp}}=335 \mathrm{MPa}, D=80 \mathrm{~mm}$ or $100 \mathrm{~mm}, t=3 \mathrm{~mm}$, $T=0 \mathrm{~min}, 30 \mathrm{~min}$ or $60 \mathrm{~min}$. Where $D, H$ and $T$ are the diameter of the steel tube, height of the column and fire duration time respectively; $t$ and fsy are the wall thickness and yield strength of the steel tube respectively and fcu is the cube compression compressive strength of concrete.

An equivalent stress-strain model presented by Han et al. [2] and the residual compressive strength of concrete heated to a maximum temperature $\mathrm{T}$ and having cooled down to the ambient temperature of $20^{\circ} \mathrm{C}$ may be found in Song et al. [3]. Fracture energy versus displacement cross crack relation is used to describe the tensile behavior of concrete.

A typical stress-strain curve for steel is given in Han et al. [4]. Elastic modulus $\left(E_{\mathrm{s}}\right)$ and Poisson's ratio $(\gamma)$ for steel after exposure to fire are taken as $2.06 \times 10^{5}\left(\mathrm{~N} / \mathrm{mm}^{2}\right)$ and 0.283 , respectively.

\section{Finite Element Model}

A finite element model was developed for the analysis of the behavior of the concrete-encased CFST column after exposure to ISO-834 fire standard. The steel tube of concrete-encased CFST column is modeled by reducedintegration shell element (S4R), and the concrete core, outer concrete as well as the end plates, modeled by 8 -node brick elements (C3D8R). The uniform loading in the $\mathrm{Z}$ direction is applied to the top surface of the end plate. The end plate connects with the steel tube by "SHELL TO SOLID" (an interface model in ABAQUS), which ensures the displacements and rotational angles of the contact elements keep the same in the whole loading process. The "tie" relation is selected for the end plate and the concrete as well as inner concrete, outer concrete and steel $[5,6]$.

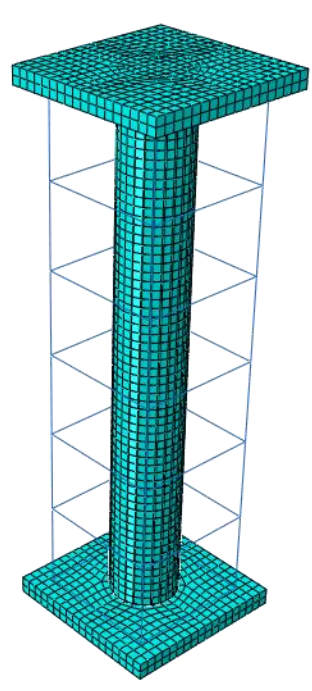

(a) Skeleton

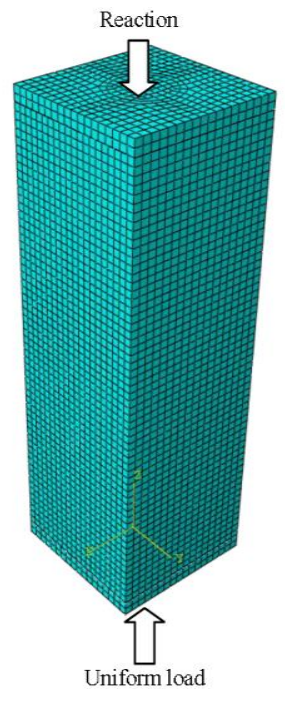

(b) Model
Figure 3. FEA model under axial compression

\section{VERIFICATION OF FEA MODEL}

In order to verify the validity of modeling and analysis 5 kinds of columns (2 for each kind) with different CFST ratio and fire duration time were designed for the axial compressive tests.

\section{A. Temperature Field In Fire}

The fire duration time is set to 60 minutes. The measured temperature results from Point 1, Point 2 and furnace are compared to the predicted data in Fig. 4. It can be found the predicted temperature curves are closed to the measured curves.

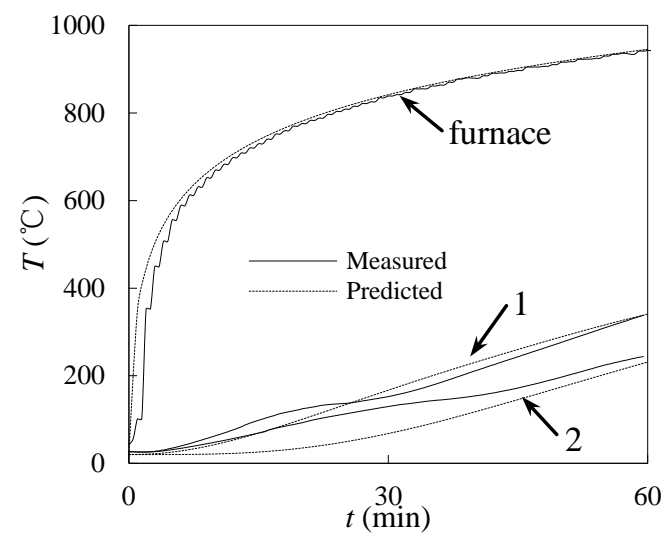

Figure 4. Comparison of $T$ - $t$ curves between measured and predicted results

\section{B. Mechanical Behavior after Exposure yo Fire}

The predicted results obtained by ABAQUS were compared to the test results as shown in Figs. 5 and 6. It can be seen that the predicted results agree well with the test results.

\section{CONCLUSIONS}

The results of the study are summarized below:

(1) The FEA model which could be used to predict the temperature field and axial compressive behavior for the post-fire concrete-encased CFST stub columns was developed.

(2) The axial compressive test results of post-fire concrete-encased CFST stub columns were used to validate the FEA model including temperature and post-fire axial compressive capacity, good agreement was achieved.

\section{ACKNOWLEDGMENT}

The research reported in the paper is part of the Project supported by the National Natural Science Foundation of China (NO. 51208135), the Program for Liaoning Excellent Talents in University (No. LR2015054) and the Project sponsored by "Liaoning BaiQianWan Talents Program" (No. 201559). The financial support is highly appreciated.

\section{REFERENCES}

[1] Linhai Han, Wei Li, Reidar Bjorhovde. Developments and advanced applications of concrete-filled steel tubular (CFST) structures: 
Members. Journal of Constructional Steel Research, 100(2014) 211228.

[2] Linhai Han, Qinghua Tan, and Tianyi Song. Fire Performance of Steel Reinforced Concrete Columns. ASCE Journal of Structural Engineering, 04(2015) 128-1-128-10.

[3] Tianyi Song, Linhai Han, Hongxia Yu. Concrete filled steel tube stub columns under combined temperature and loading. Journal of Constructional Steel Research, 66(2010) 369-384.
[4] Linhai Han. Fire performance of concrete filled steel tubular beamcolumns. Journal of Constructional Steel Research, 57(2001) 697-711.

[5] Linhai Han, Jingsi Huo, Yongchang Wang. Compressive and flexural behaviour of concrete filled steel tubes after exposure to standard fire. Journal of Constructional Steel Research, 61(2005) 882-901.

[6] Zhong Tao, Mohamed Ghannam, Tianyi Song, Linhai Han. Experimental and numerical investigation of concrete-filled stainless steel columns exposed to fire. Journal of Constructional Steel Research, 118(2016) 120-134.

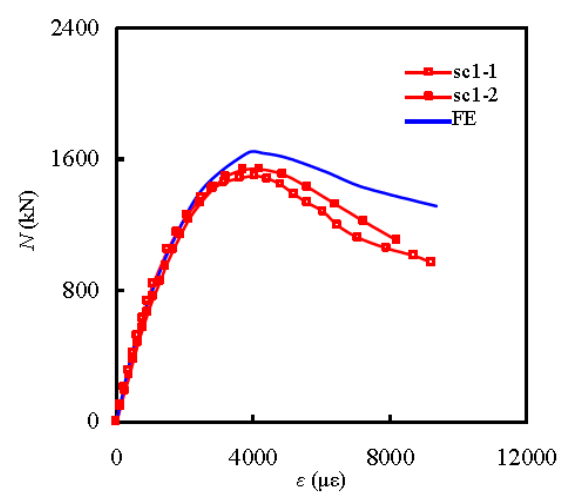

(a) $\mathrm{sc1}$

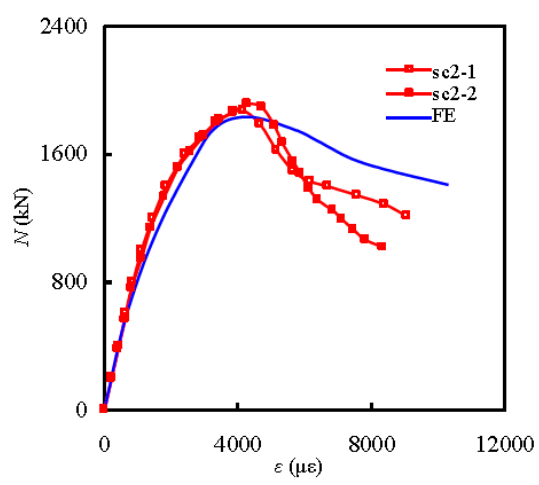

(b) $\mathrm{sc} 2$

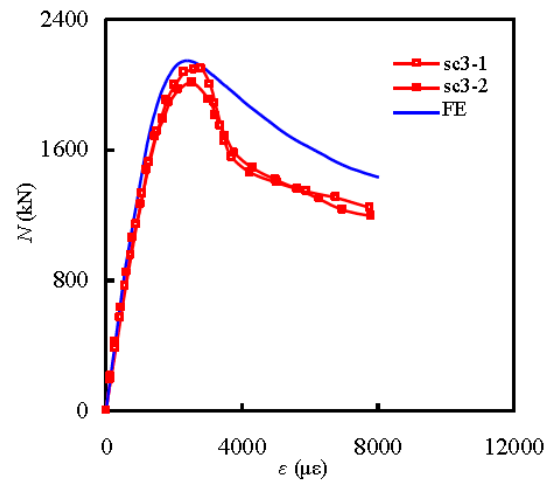

(c) $\mathrm{sc} 3$

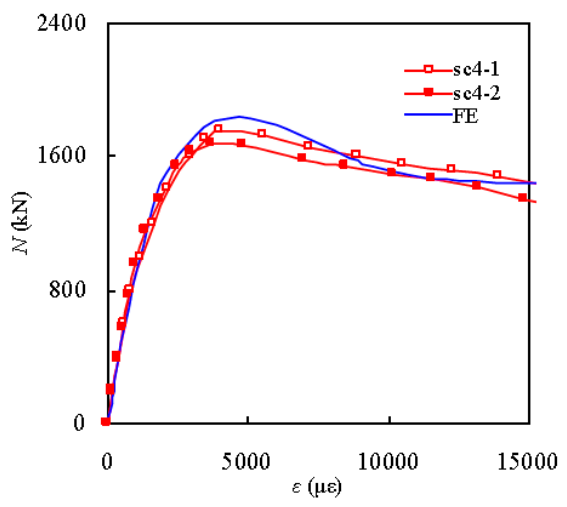

(d) $\mathrm{sc} 4$

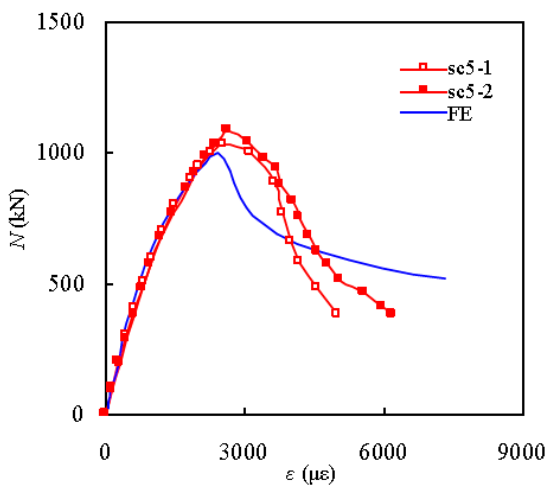

(e) $\operatorname{sc} 5$

Figure 5. Comparison of $N-\varepsilon$ curves between measured and predicted results 


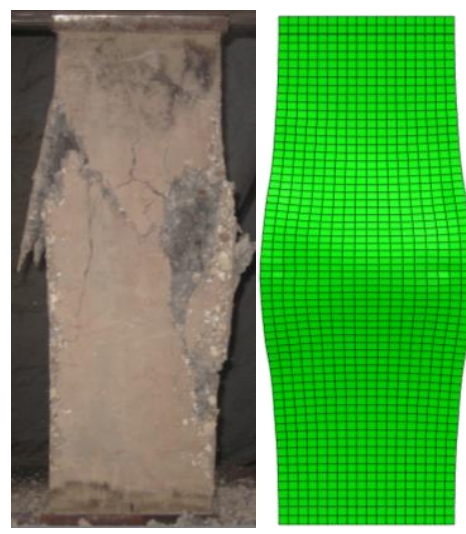

(a) $\mathrm{sc} 1$

(d) sc4

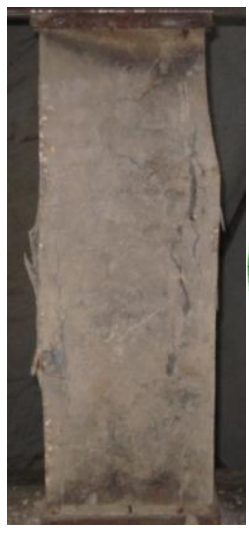

(b) $\mathrm{sc} 2$

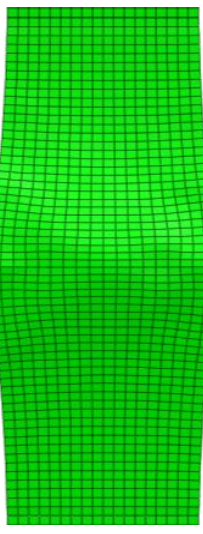

(c) $\mathrm{sc} 3$

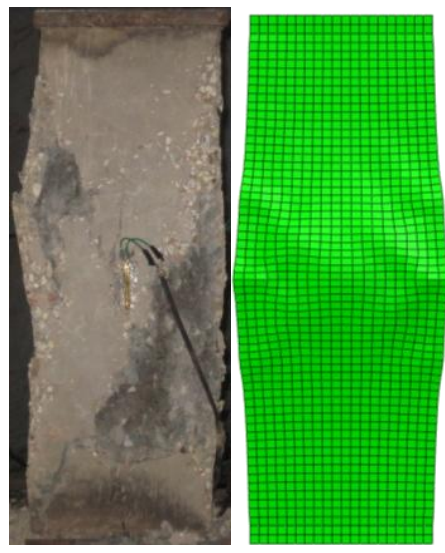

(e) $\operatorname{sc} 5$
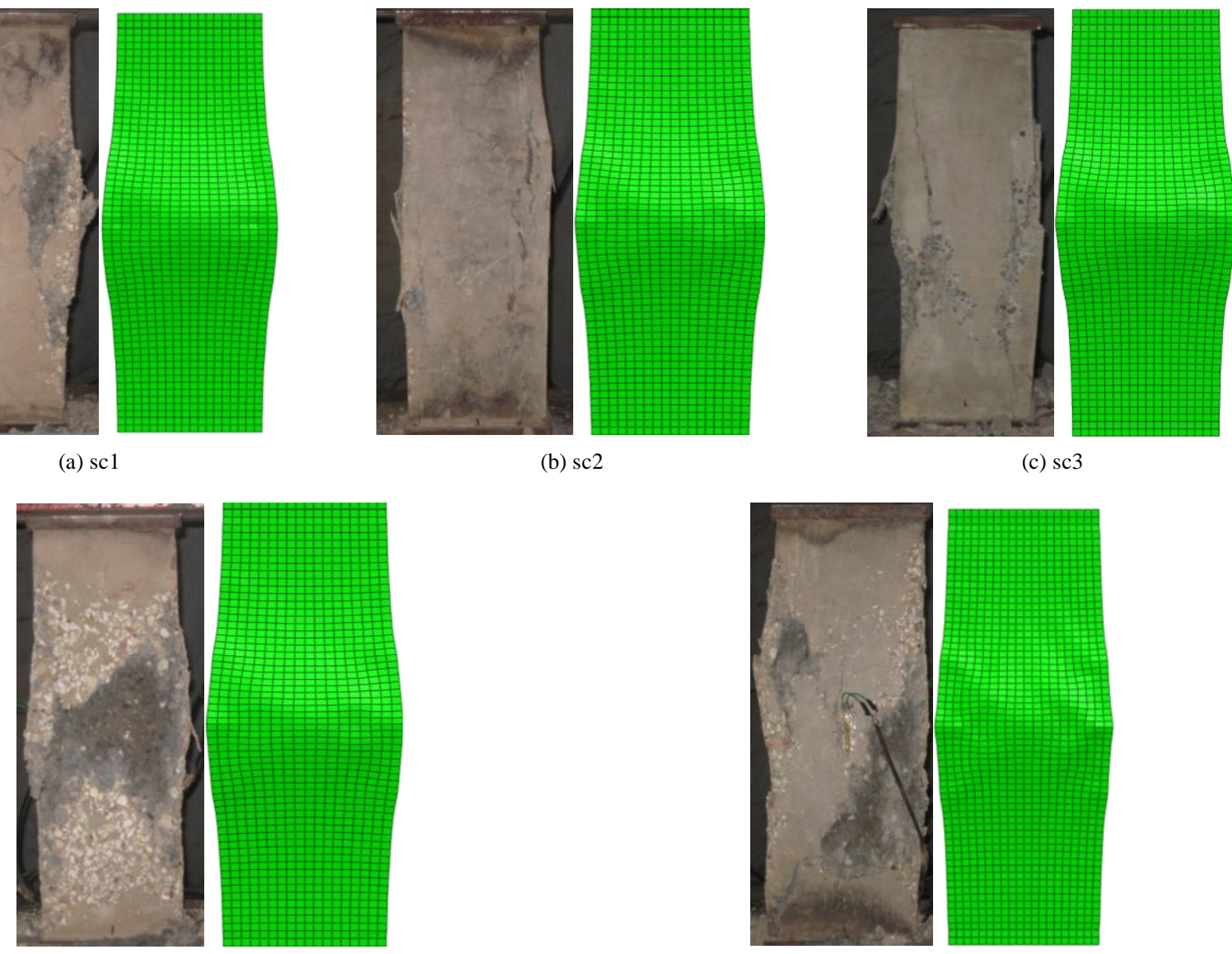

Figure 6. Comparison of failure modes 